\title{
Improving risk identification process in project management
}

\author{
Allan de Godoi Contessoto, Laís Andreoli Sant’ Ana, Rogéria Cristiane Gratão de Souza, Carlos Roberto Valêncio, Geraldo \\ Francisco Donegá, Anderson Rici Amorim and Antonio Marcos Neves Esteca. \\ Department of Computer Science and Statistics, São Paulo State University, São José do Rio Preto, São Paulo Brazil. \\ \{allan.contessoto, lais.andreoli, zafalon, anderson.rici, am.esteca\}@sjrp.unesp.br, \{rogeria, valencio\}@ibilce.unesp.br
}

\begin{abstract}
Nowadays there are many information systems which aim the decision-making, automating the processes of project management. However, many times these systems limit the specific functions related to risk management processes and do not allow the control and effective treatment of uncertain events that may affect the project goals. Thus, this paper proposes the integrated use of the Delphi Technique and Risk Breakdown Structure - RBS in order to contribute to the identification of risks, considering the opportunities and threats in a project, to enhance the beneficial effects of the opportunities and avoid the harmful effects of threats. For the evaluation of the results, it was performed the improvement of a system called System to Aid Project Managing - SAPM, in order to support the automated execution of risk management with an emphasis on risk identification process, since this is a crucial stage for risk management in projects. As a result of this work, it is observed that the combined use of the Delphi Technique and RBS allows the risk identification process can be performed fast and safely through the anonymity of those involved and global visualization of the project.
\end{abstract}

Keywords - Risk Management, Delphi Technique, Risk Breakdown Structure, System to Aid Project Managing.

\section{INTRODUCTION}

The project management is becoming increasingly important in all sectors of the economy, since it provides an environment that allows users to manage the complexity of the projects, considering their restrictions and requirements [1]. A project can be understood as a temporary effort to create a product, service or exclusive result to satisfy the customer needs. Thus, project management is the application of knowledge, abilities, tools and techniques in the project processes, in order to achieve some goals [2].

The Project Management Body of Knowledge - PMBoK [2] describes an efficient management through the application of ten knowledge areas. Among them, there is the risk management applied to reduce the probability of occurrence of harmful events and creates answers to these events, besides increases the probability of occurrence of helpful events to the project and actions for achieving these events. A risk is defined as an event or an uncertain condition that, if it occurs, it will cause a positive or negative effect to, at least, one goal of the project. When a risk may cause a positive effect, it is named opportunity, however, when the risk may cause negative effect, it is named threat $[2,3]$.

In order to assist the decision-making of managers many computational tools have been developed $[4,5,6]$. However, few available tools have features that comply with the guidelines proposed by the PMBOK, primarily for the treatment of risk management, which results in difficulties for the correct application of this knowledge area.
In this scenario, the present work aims to promote the integrated use of support techniques to identify the risks efficiently and safely, contemplating the activities for the successful completion of the management of the opportunities and threats of a project. Thus, we adopted the Delphi Technique and Risk Breakdown Structure, which were incorporated into the System to Aid Project Managing SAPM [6], aiming to expand its features for the correct evaluation of proposed risk identification process.

\section{RISK MANAGEMENT}

The risk management is proposed by PMBoK guide as a set of six processes, which interact among them and with other knowledge areas. Each process occurs at least once per life cycle of the project [2]. The risk identification process is crucial for the efficient execution of risk management in projects because the wrong identification of risks influences directly in the failure of a product or service, because it is difficult to manage something not well known [8]. Therefore, the project managers must promote actions to provide a complete and comprehensive identification of risks.

For the selection of risk identification techniques in this study were considered the main techniques described in the PMBoK guide because they are very accepted and disseminated among the professionals. As a result to improve the efficiency of risk identification process was proposed the use of Delphi Technique combined with Risk Breakdown Structure (RBS). Therefore, when a risk is identified by Delphi Technique and its characteristics are documented, it is essential to introduce of RBS to provide a project overview.

The Delphi Technique may be used to identify risks by consensus of specialists in order to obtain their opinion anonymously. Thus, the specialist, who is the mediator, uses a questionnaire to ask ideas about project risks. Then, the responses are summarized and redistributed anonymously to participants to assess each risk identified. After a few evaluation rounds, the consensus is obtained. Therefore, the Delphi Technique helps to reduce data partiality because it prevents personal influence on identified risks $[2,8]$.

The RBS was developed with the aim of interpret easily and directly the risk definition and assist managers to identify the risks in an organization. The RBS considers several risk sources to promote a vision over all parts of the project, and assist in the identification of recurrent themes and project areas with risk concentration. The RBS provides risk identification in a structured format and each lower level represents a more detailed definition of project risk sources [7].

In the literature there are many studies to provide the refinement and development of risk management $[9,10]$. Due 
to area advances, the RBS has been consolidated along the years as one of the essential techniques for correct application of risk management $[7,11]$. However, the exclusive use of the RBS is not enough for the identification and characterization of risks, because it is a visualization technique. Thus, there is the need for the combination of RBS with some information gathering technique. Due to its anonymity characteristics, which enable change of opinions without personal influences in the results, the Delphi Technique is the best option for the combined use with the RBS. Therefore, it was found that the use of Delphi Technique with Risk Breakdown Structure allows managers to perform efficiently identification of threats and opportunities by a global view of the project.

\section{METHODOLOGY}

The methodological process adopted for the realization of the project comprises three stages. In the first stage, we have analyzed computational tools to support the risk management, in order to identify the main functionalities and show the strongest and the weakest points of each tool. The chosen tools are: Microsoft Project (MS-P) [12], NetProject (Net-P) [13], dotProject (dot-P) [14] and SAPM [6]. The theoretical support to analyze these tools was based on the processes from the risk management of PMBoK, in addition to relevant papers in risk management. As a result, we noticed the lack of computational mechanisms to help the identification of the project risks. Thus, it was possible to determine the functional requirements needed to enhance the SAPM in order to provide improvements to supply the shortcomings found on the analyzed tools.

In the second stage, it was developed the expansion of the SAPM, in order to consider the identified functional requirements to provide computational resources to support the identification of risks, through the development of an automated RBS and the execution of the Delphi Technique. For the development, we used open computational resources, as PHP, HTML and JavaScript languages, MySQL server to the database system management and Apache web server.

Lastly, in the third stage, the expansion of SAPM allowed performing an evaluation process which is divided into three distinct phases: the first one is to evaluate the efficiency of characterization of risks in threats and opportunities; the second aims the analysis of the ease of use of the new functions added to SAPM to risk identification; the third is to verify the general efficiency of the adopted methods to risk management.

The first evaluation phase was done by 16 professional from many areas that apply the risk management in their daily activities. This stage occurred to evaluate the significance of the functions responsible for the given treatment to the opportunities and to the threats, since in the correct risk management, threats and opportunities demand the same attention. The participants were trained to a correct utilization of the SAPM functions, as well as the focus of the conducted evaluation. The SAPM was available to use 15 days long. Then, the participants answered an evaluation form, scoring from 0 to 10 each evaluated function. Moreover, the participants could contribute with comments, emphasizing the strongest and the weakest points identified, and the practicality of the functions as well.

The second evaluation phase was done by nine professionals divided into two groups, in order to use the mechanisms of risk identification in different contexts, resulting, thus, in two case studies. Each group received a practical training about the functions of SAPM, but more specifically about the functions related to the RBS and Delphi techniques. Thus, after the training, the two case studies were monitored by a period of 15 days, which the participants used the Delphi Technique and RBS to simulate the identification of risk on a dummy project. After this period, the participants answered the evaluation questions about the ease of use integrated of the Delphi and RBS techniques.

Finally, the third evaluation phase was done by 30 professionals that received training about all functions of the SAPM related to the correct application of risk management. In this evaluation stage, the participants used the SAPM for a period of 15 days, applying the risk management to their daily activities. Thus, as the previous stages, the participants answered an evaluation form with questions related to the use of the whole system. Therefore, in the third stage, it was analyzed all the functions of the risk management, considering the support that the set of functions provides to the correct applying of risk management, as well as whether the execution of these functions makes more agile and comprehensive the application of this knowledge area.

\section{RESULTS}

This section brings the results obtained with the methodological process adopted as well as an analysis of them. Table 1 shows the results of the analysis performed for each tool, considering two aspects: the first one is related to the use or not of functions that represent crucial resources to an efficient risk management and the second one refers to the percentage of support that each tool offers considering the risk management processes described in the PMBoK guide.

Table 1 - Analysis of computational tools

\begin{tabular}{ccccc} 
& MS-P & Net-P & dot-P & SAPM \\
\hline $\begin{array}{cccc}\text { Functions } \\
\text { Risk identification technique }\end{array}$ & No & No & No & No \\
RBS crating graphically & No & No & No & No \\
Documentation & Yes & Yes & Yes & Yes \\
Historical basis & No & Yes & No & No \\
To plan risk management & 0 & 0 & 0 & 0 \\
Risk identification & 0 & 40 & 80 & 40 \\
Qualitative risk analysis & 0 & 0 & 80 & 0 \\
To plan risk responses & 0 & 20 & 60 & 0 \\
To control plan & 0 & 0 & 40 & 0 \\
To plan risk management & 0 & 0 & 0 & 0
\end{tabular}

With the results of this stage of empirical study, it is possible to notice that analyzed tools treat superficially the risk management, when considered the good practices proposed by $\mathrm{PMBoK}$ guide. Another constraint observed in 
the analysis is the complete lack of computational resources to give efficient support to the characterization of risks during their identification, distinguishing threats and opportunities. For the correct application of risk management is essential that the treatment given to threats and opportunities is the same. Considering the risk is frequently associated to negative aspects in projects, i.e., the threats, the treatment of opportunities is compromised, reducing the effectiveness of the application of risk management in projects. Throughout the analyzes presented, a set of functional requirements was established to overcome the observed shortcomings.

The implementation had the aim to offer functions concerning risk management in the SAPM through the identified requirements. From the inclusion of an opportunity or a threat, where the characteristics are described, the RBS is automatically built. The Figure 1 shows the initial interface of RBS in list format. It is important to mention that the insertion of a threat or an opportunity occurs in the same form, which highlights the same approach for both.

During the first phase of the evaluation process we were able to confirm the relevance of the functions implemented in SAPM to approach opportunities and threats in the same way. In the histograms presented in the Figure 2 we can verify the evaluation of each criterion analyzed. Through the grades in the histograms it is possible to notice that the participants certified that the functions provided an efficient approach for opportunities and threats, simplifying the application of risk management in a project.

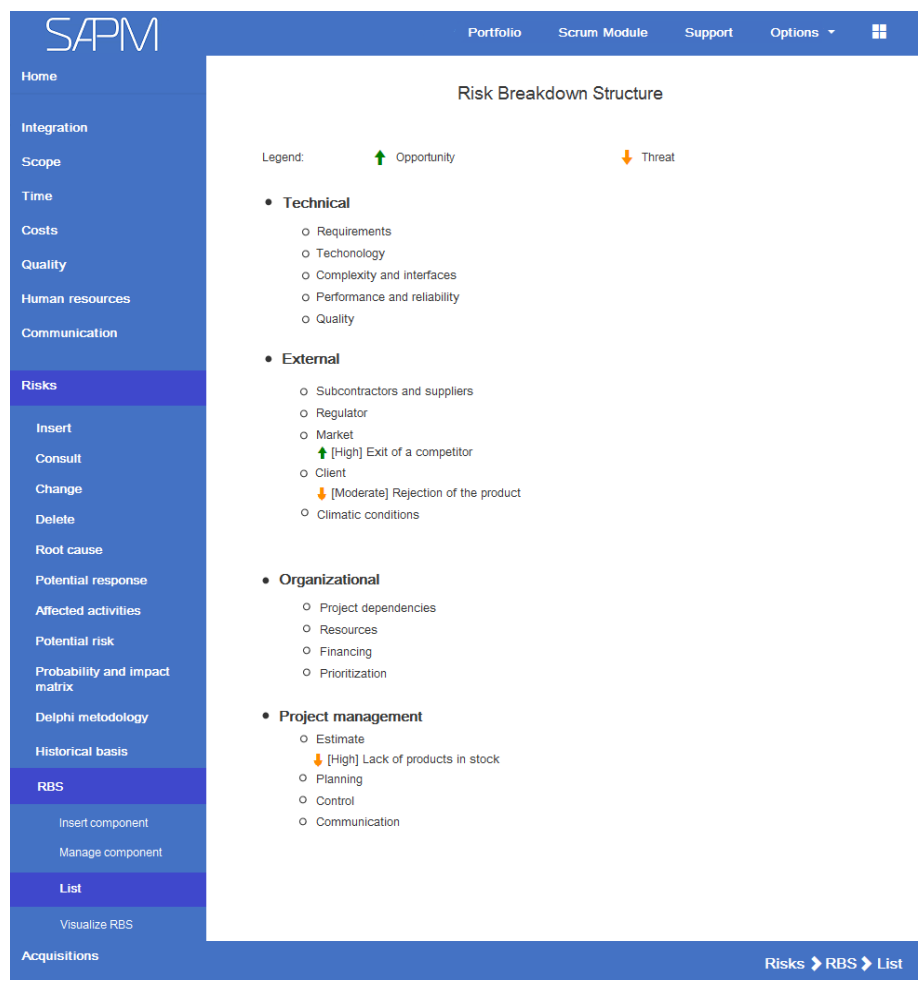

Figure $1-\mathrm{RBS}$ in a list format
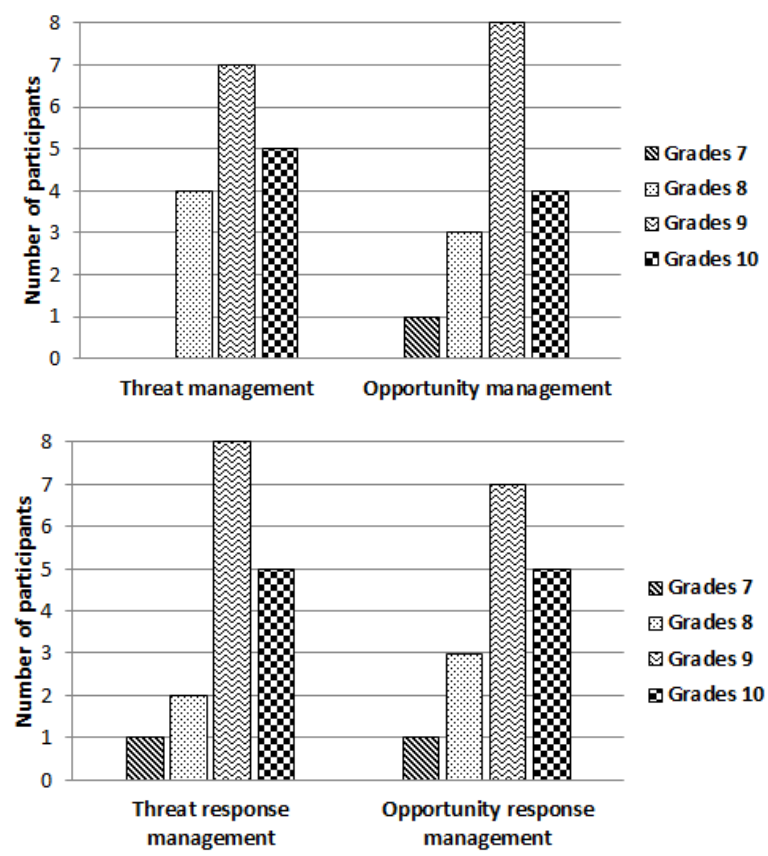

Figure 2 - Evaluation of treatment of opportunities and threats

The second phase of the evaluation process was performed through two case studies, i.e., Delphi Technique and RBS, to verify the efficiency and agility of approaches to identify the risks. In each case study has occurred an appointment of a mediator and the criterions for choice were education level and experience in risk management. Initially, in both case studies, each participant had the access to information related to the project and then they could develop a list of risks. In the following, the mediator analyzed all the identified risks to refine and eliminate potential redundancies, which resulted in a list of risk of mediator. After the phase of mediator's analysis, all the participants had the access to the list of risk proposed by mediator to add new risks and insert some comments. All process was performed during two complete rounds, because the mediators deemed that consensus had already been established. It is important to note that in huge and complex projects many iterations can occur to reach the consensus.

We observed in both case studies that were identified more threats than opportunities, being nine in the first case and five in the second one, while the opportunities were four and three respectively. This fact shows clearly the difficult of the participants to identify opportunities which can be explained by the negative connotations associated with term risk. Generally, risk gives an idea of something must be minimized, avoided, or that is related with danger or fault. Thus, it is possible to emerge that the inclusion of mechanisms to support the treatment of opportunities together with the treatment of threats are a good choice, proving a more comprehensive risk management.

Finally, with the results of the third phase is possible to observe the efficiency and the ease of use of SAPM's expansion. The Figure 3 shows the obtained results of this phase of the evaluation process. 


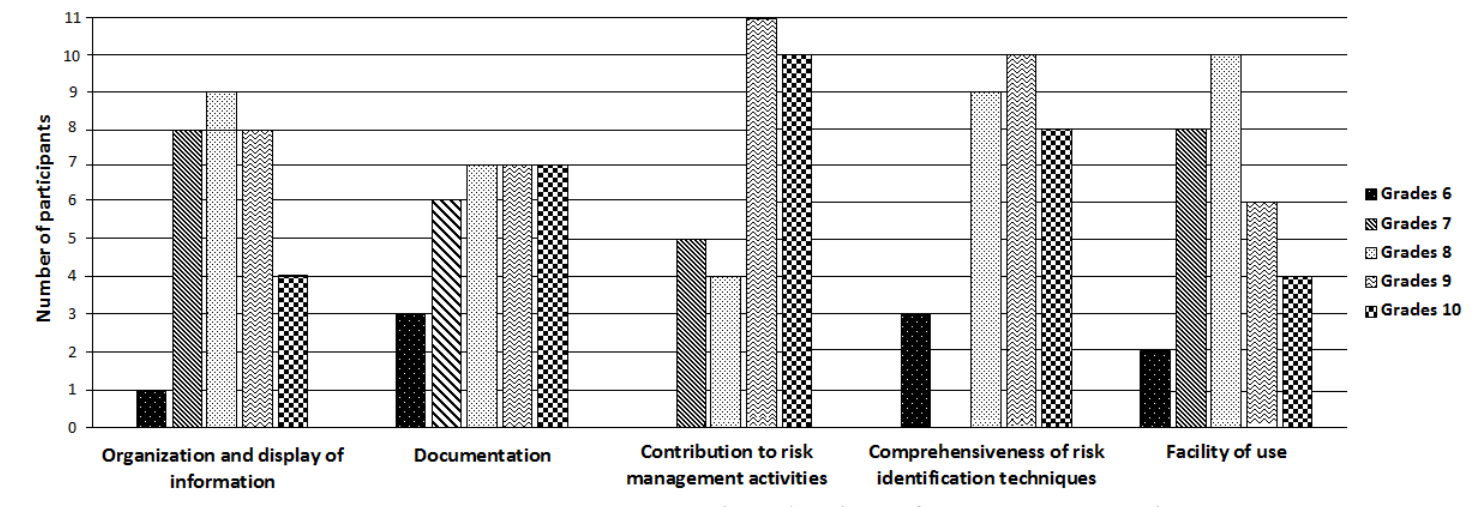

\section{CONCLUSION}

This paper presented mechanisms to support an efficient risk management in projects with the focus on the risk identification process. Thus, the control of project opportunities and threats offered can contribute to managers make decisions based on recent and reliable information.

The relevance of combined use of Delphi Technique with RBS was attested through the functionalities embedded in the SAPM which were evaluated by a three-step process. Such process reinforce the importance of functions implemented to perform the correct risk management following best practices proposed by $\mathrm{PMBoK}$ guide. Thus, it is possible to infer that the project risks can be properly identifed, answered and supervised through the combined use of Delphi Technique and RBS.

The use of techniques to assist managers during risk identification is very important since faults in the implementation process compromises entire performance of risks management, which can cause difficulties for completion of the project objectives. The automated creation of RBS allows project managers visualizing the points that have the highest concentration of uncertainties during entire project life cycle. As perspective for future works, we intend to developed methods to assist managers for planning responses to the risks, as well as automated methods which indicates the probability of occurrence and impact. Moreover, should be set support resources to encourage the use of Risk Management Maturity Model [15] by organizations, through the definition of a method that can support the progress between the maturity levels set by the model. Finally, we are able to conclude the present study contributed to effective risk identification in a project with automated support through the expansion of SAPM, using Delphi Technique and RBS together.

\section{REFERENCES}

[1] R. S. Pressman, "Software Engineering: A Practitioner's Approach", 7th edition, 2010.

[2] PMBoK, "A Guide to the Project Management Body of Knowledge", 5th edition, Project Management Institute - PMI, 2013.

[3] Gregoriades, A., Lesta, V. P., and Petrides, P., "Project Risk Management Using Event Calculus", In Proceedings of the 23th International Conference on Software Engineering and Knowledge Engineering (SEKE), p. 335-338, Miami, USA, 2011.
[4] Fontoura, L. M., and Price, R. T., "Systematic Approach to Risk Management in Software Projects through Process Tailoring" In Proceeding of the 20th International Conference on Software Engineering and Knowledge Engineering (SEKE), p. 179-184, São Francisco, USA, 2008.

[5] Tosun, A., Bener, A., and Kocaguneli, E., "BITS: Issue Tracking and Project Management Tool in Healthcare Software Development", In Proceedings of the 21th International Conference on Software Engineering and Knowledge Engineering (SEKE), p. 526-529, Boston, USA, 2009.

[6] R. C. G. Souza, A. M. N. Esteca, A. B. Santos, C. R. Valêncio, and M. T. Honda, "Web System to Aid Project Management", In Proceedings of the 23th International Conference on Software Engineering and Knowledge Engineering (SEKE), p. 325-330, Miami, USA, 2011.

[7] D. Hillson, "Using a Risk Breakdown Structure in project management", Journal of Facilities Management, v.2, p. 8597, 2003.

[8] J. L. Worrell, P. M. Di Gangi, A. A. Bush, "Exploring the use of the Delphi method in accounting information systems research", International Journal of Accounting Information Systems, v. 14, n. 3, p. 193-208, 2013.

[9] M. B. Junkes, A. P. Tereso, S. P. Afonso, "The importance of risk assessment in the context of investment project management: A case study", Computer Science, v. 64, p. 902 910, 2015.

[10] S. Alhawari, L. Karadsheh, A. N. Talet, E. Mansour, "Knowledge - based risk management framework for information technology project", International Journal of Information Management, v. 32, n. 1, p. 50 - 65, 2012.

[11] D. Hillson, "Using a Risk Breakdown Structure in project management", Journal of Facilities Management, v. 2, p.85 - 97, 2003.

[12] Microsoft Project, https://products.office.com/enus/project/project-and-portfolio-management-software.

[13] NetProject, http://www.netproject.com.br/.

[14] dotProject, http://www.dotproject.net/.

[15] A. Serpell, X. Ferrada, L. Rubio and S. Arauzo, "Evaluating risk management practices in construction organizations", In Procedia-Social and Behavioral Sciences, v. 194, p. 201-210, 2015. 